\title{
Perspectives of the industrial recycling of hard- alloy materials waste by electro-erosive grinding
}

\author{
Kharis Rakhimyanov ${ }^{1, *}$, and Valentina Marusina ${ }^{1}$ \\ ${ }^{1}$ Novosibirsk State Technical University, Faculty of Mechanical Engineering and Technologies, \\ 630073 Prospekt K. Marx 20, Novosibirsk, Russia
}

\begin{abstract}
The creation of efficient industries is possible by using sustainable technologies based on the processes of recycling of the production waste. First of all, it refers to expensive material waste, including hard alloys. The electro-erosive grinding is considered to be the effective method of recycling such materials. The results of research on recycling the tungsten-cobalt hard alloy show the possibility of obtaining tungsten-carbide powders possessing improved physical and mechanical properties. The technology mentioned is also perspective for recycling tungstenless hardalloy waste both at the laboratory devices equipped with the RC-generator and at the industrial installations of bulky grinding. It is established experimentally that the electro-erosive grinding of the TN20 tungstenless hard alloy at the laboratory provides obtaining the main volume (up to $85 \%$ ) of the powder particles of the spherical shape having a dimension of $5 \mu \mathrm{m}$ and the specific surface of $31.5 \mathrm{~m}^{2} / \mathrm{g}$. Higher physical and mechanical properties of powders are also provided during recycling the TN20 alloy waste at the industrial installations of bulky grinding.
\end{abstract}

\section{Introduction}

Nowadays materials based on carbides and nitrides of the transition materials are more and more widely used. It is explained by the unique combination of mechanical, thermal and physical properties, including the high temperature of melting, ductility at high temperatures, high hardness, wear resistance and some others, which allows referring them to high-impact and high-melting materials. The same feature refers to carbides of such metals as tungsten and titan, which are widely used in the powder metallurgy for obtaining hard alloys. In spite of the fact that tungsten carbide is not the hardest and high-resistant of the transition metals, its hardness is unchangeable [1] and in increasing the temperature from $300 \mathrm{~K}$ to 1, 200 $1,300 \mathrm{~K}$ it decreases less in comparison with other carbides. Besides, it possesses a higher hardness module and considerably less coefficient of thermal expansion among the carbides of the transition metals. The inherent complex of tungsten carbide properties provides its wide use to obtain hard alloys, which nowadays are considered as the main tool material for metal processing and drilling operations.

\footnotetext{
*Corresponding author:kharis51@mail.ru
} 
Obtaining polycrystalline carbides is accomplished by the synthesis using different methods of powder metallurgy [2 -5]. The main methods are the synthesis from a metal and carbon or of the compositions containing the metal oxide or chloride and carbon (hydrocarbon or CO) [6]. The presented technologies are the main for obtaining tungsten and titanium carbides as a raw material for the further manufacturing of a hard alloy.

However, at present sustainable technologies, including non-waste technologies, are of a particular interest in creating effective industries. They are based on the processes of recycling the production waste. One of the effective methods in recycling the hard alloy waste is the electro-erosive grinding. The results of the investigations presented in Papers [7 - 11] show that it is possible to obtain tungsten carbide powders with improved physical and mechanical properties by the electro-erosive grinding of the tungsten-cobalt hard alloy waste.

The recycling of the hard alloy of the WC-Co group is possible by simple mechanical grinding, but this technology is not effective for tungstenless hard alloys.

The paper under consideration is devoted to investigating the possibilities of using the electro-erosive grinding with the RC-generator and bulky grinding of hard alloy waste VC8 and TN20 as well as to assessing the perspectives for the industrial implementation of the technology mentioned.

\section{Results and discussion}

The experiments on studying the electro-erosive grinding of alloys VC8 and TN20 were conducted. The powder obtained during the electro-erosive grinding of VC8 alloys in the industrial oil with using the $\mathrm{RC}$-generator is a mixture mainly of tungsten carbides of the cubic modification $\beta-\mathrm{WC}, \mathrm{W}_{2} \mathrm{C}, \beta-\mathrm{Co}$ (Figure 1) with a specific surface $68.4 \mathrm{~m}^{2} / \mathrm{g}$ which has a wide size range $(0-25 \mu \mathrm{m})$. In this case the impulse energy (E) was equal to $0.02 \mathrm{~J}$ and the impulse duration $(\tau)$ was $20 \mu \mathrm{c}$.

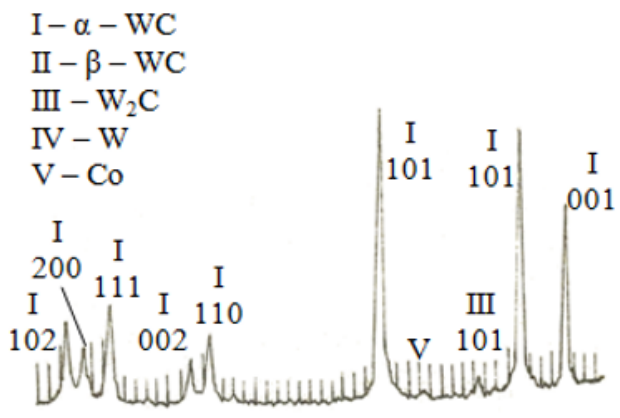

a

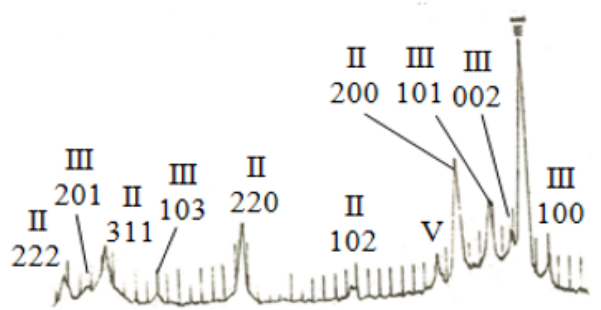

b

Fig. 1. X-ray diagrams of the initial powder (a) and grinded powder VC8 (b) in the industrial oil

The grain-size analysis of the powder VC8 made on the Sedigraf-5 000D device is shown in Table 1.

Table 1. Grain-size analysis of the VC8 powder

\begin{tabular}{|l|c|c|c|c|c|c|}
\hline Powder size, $\mu \mathrm{m}$ & $\begin{array}{c}0- \\
0,5\end{array}$ & $0,5-1$ & $1,0-2.5$ & $2,5-5$ & $5,0-8$ & $8,0-25$ \\
\hline Powder volume, \% & 3,7 & 8 & 46 & 18 & 20 & 4,3 \\
\hline
\end{tabular}

The particle distribution according to their size obtained by the static processing of the results is asymmetrical with the shift to the range $1.0-2.5 \mu \mathrm{m}$. 
The powder containing mainly the titanium carbide (TiC), a small amount of the molybdenum carbide (MoC), the polycarbide $\left(\mathrm{Mo}_{2} \mathrm{C}\right)$ and the nickel carbide $\left(\mathrm{Ni}_{2} \mathrm{C}\right)$ as well as $\mathrm{Ni}, \mathrm{Ti}$, and Mo was obtained in grinding the alloy waste TN20 at the same operating characteristics of the electric spark.

The obtained powder also has a wide size range $(0-30 \mu \mathrm{m})$ with a specific surface 31.5 $\mathrm{m}^{2} / \mathrm{g}$. The particle shape to $5 \mu \mathrm{m}$ (up to $85 \%$ in the bulk) is mainly spherical. The particles with a dimension of more than $5 \mu \mathrm{m}$ are mainly the conglomerates of irregular shape.

Figure 2 presents the particle distribution of the powders TN20 (Figure 2a) and VC8 (Figure $2 \mathrm{~b}$ ) in using the RC-generator.

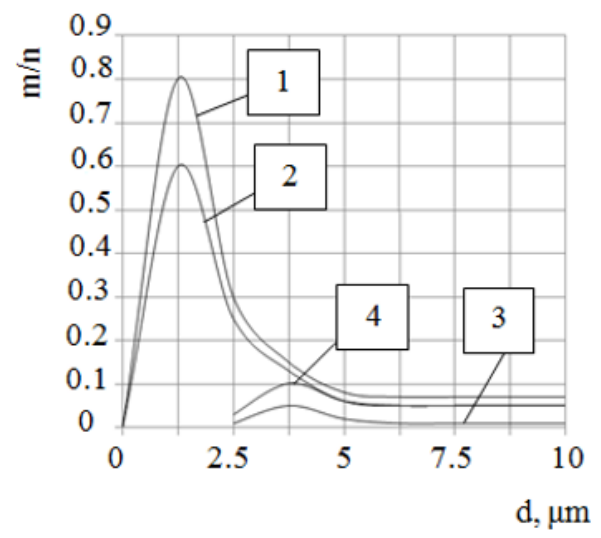

a

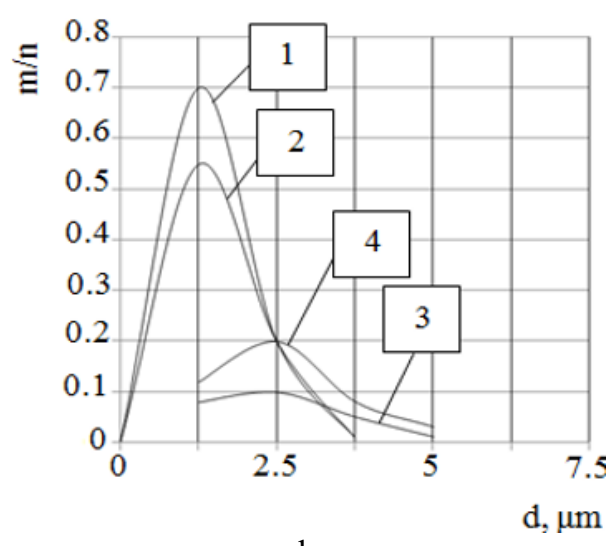

b

Fig. 2. Ratio of the particle number of spherical $(1,2)$ and irregular $(3,4)$ shape obtained by grinding with the use of the RC-generator at $\mathrm{c}=4 \mu \mathrm{F} ; \mathrm{E}=0.004 \mathrm{~J} ; \tau=15 \mu \mathrm{c}$ (curves 1,3 ); $\mathrm{c}=16 \mu \mathrm{F} ; \mathrm{E}=$ $0.15 \mathrm{~J} ; \tau=32 \mu \mathrm{c}$ (curves 2,4 ):

$\mathrm{a}-\mathrm{TiC}$ powder obtained in grinding the TN20 alloy;

b - $\beta$-WC powder obtained in grinding the VC8 alloy

Because the further use of powders in many cases is connected with sintering, it is necessary to have the information concerning the transition process of the metastable cubic modification of the tungsten carbide in the stable condition to assess the technological possibilities of the $\beta-\mathrm{WC}$.

So, the powder was annealed at temperatures of $200-900^{\circ} \mathrm{C}$ in vacuum $1.33 * 10^{-4} \mathrm{H} / \mathrm{m}^{2}$ at the same heating speed as in sintering.

The change in integral intensities $I_{\alpha-W C}(101)$ and $I_{\beta-W C}(111)$ depending on the temperature is shown in Figure 3. The ratio of the phase integral intensities in the temperature range $600-900^{\circ} \mathrm{C}$ confirms the diffusion character of their transition (Figure 4).

The ratio of the phase integral intensities is determined by the following formula:

$$
K=\frac{J_{\alpha}(W C(101))}{J_{\beta}(W C(111))+J_{\alpha}(W C(101))}
$$

The investigations showed that at temperature of $900^{\circ} \mathrm{C}$ the full transition of $\beta-\mathrm{WC}$ in $\alpha$ - WC was obtained. In this case the activation energy was equal to $41 \mu \mathrm{J}$.

Besides, the experiments on the bulky electro-erosive grinding of the TN20 waste were conducted with the following operating parameters: capacity $27 \mu \mathrm{F}$, electrical power -15 $\mathrm{kVA}$, pulse voltage $520-560 \mathrm{~V}$. 


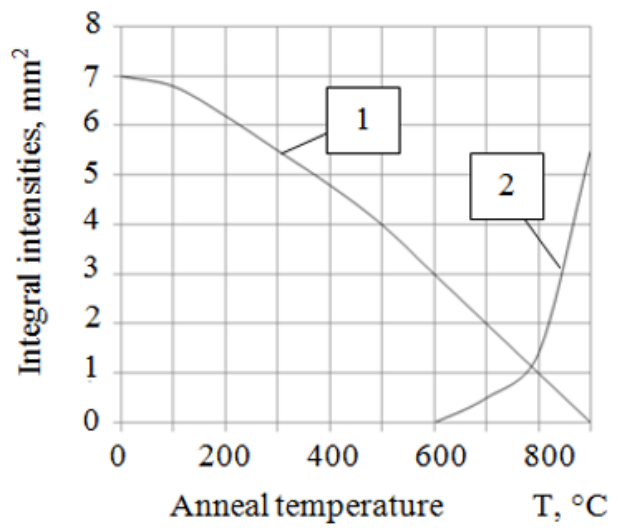

Fig. 3. Change in integral intensities during the phase transition depending on the anneal temperature:

$1-\mathrm{J}_{\beta}(\mathrm{WC}(111)) ; 2-\mathrm{J}_{\alpha}(\mathrm{WC}(101))$

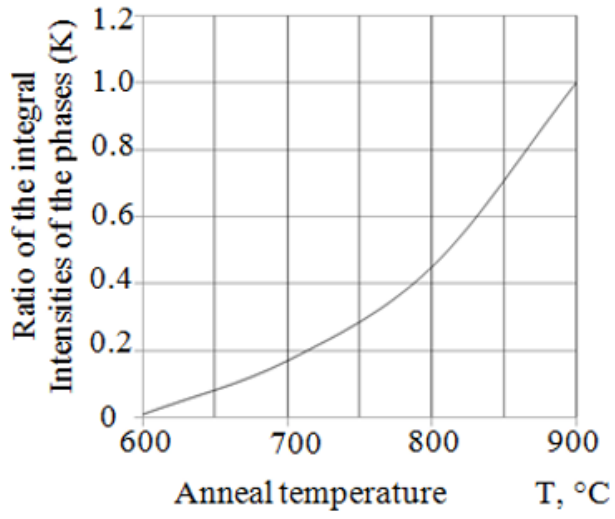

Fig. 4. Change in the ratio of the integral intensities of the carbide phases depending on the anneal temperature

The bulk grinding is accomplished in the reactors both with a vertical and horizontal arrangement of electrodes in which the hard alloy waste is located. The working liquid (industrial oil) is supplied in the reactor (Figure 5). A high productivity of the process is provided in this case by the appearance of a great number of the discharge channels with their migration along the whole layer of the waste during one current pulse.

The powder as a result of the bulky grinding is similar in the composition and size to the powder obtained at the laboratory installation with the RC-generator.

The particles with a size of up to $7 \mu \mathrm{m}$ are of spherical shape, which volume reaches $85 \%$. The particles with a size of more than $7 \mu \mathrm{m}$ is the particle conglomerates of spherical shape. The specific surface of the powder is equal to $25.2 \mathrm{~m}^{2} / \mathrm{g}$.
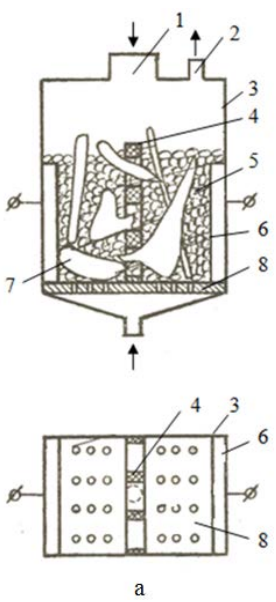

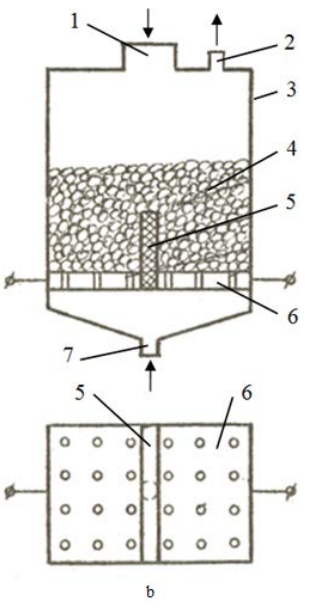

Fig. 5. Reactor constructions for bulky grinding:

a - with a vertical arrangement of the electrodes: 1- raw material supply; 2 - suspension removal;

3 - dielectric case; 4 - perforated dividing plate; 5 - grains of the metal; 6 - electrodes; 7 - scissels;

8 - distribution grid; 9 - supply of the working liquid;

$\mathrm{b}$ - with a horizontal arrangement of the electrodes: 1 - raw material supply; 2 - suspension removal; 3 - dielectric case; 4 - metal grains; 5 - dielectric dividing plate; 6 - electrodes; 7 supply of the working liquid 
The X- ray diagram of the powder obtained during bulky grinding of the TN20 plates is shown in Figure 6.

The information about physical and mechanical properties of the powders obtained by the electro-erosive method from the manufacturing waste during grinding of the VC8 and TN20 alloys is presented in Table 2. The change in physical and mechanical properties of the VC8 grinded powder after annealing is shown for comparison.

The investigations of powders under the ultrasonic impacts showed that grinded powders possessed a higher resistance to contact loads. It is proved by the values of the powder specific surfaces before and after ultrasonic tests. The results show a higher abrasive capacity of grinded powders.

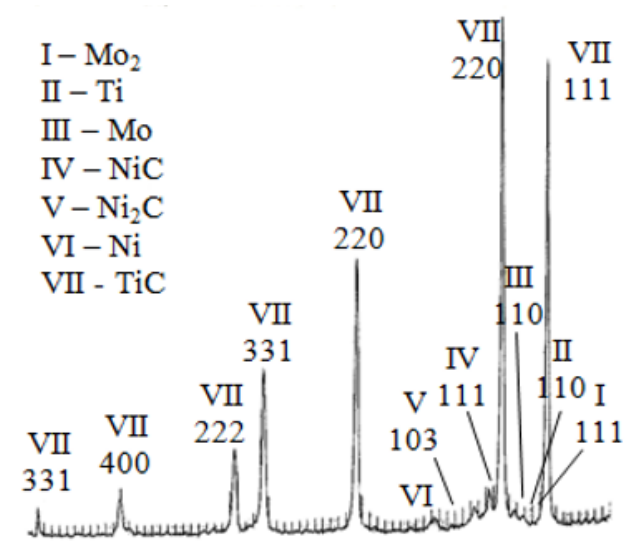

Fig. 6. X-ray diagrams of the TN20 powder under bulky grinding

Table 2. Abrasive capacity and the specific surface of the powders

\begin{tabular}{|l|c|c|c|}
\hline \multicolumn{1}{|c|}{ Powder } & $\begin{array}{c}\text { Abrasive } \\
\text { capacity, } \mathrm{g}\end{array}$ & $\begin{array}{c}\text { Specific surface, } \\
\mathrm{m}^{2} / \mathrm{g}, \\
\text { before tests }\end{array}$ & $\begin{array}{c}\text { Specific surface, } \\
\mathrm{m}^{2} / \mathrm{g}, \\
\text { after tests }\end{array}$ \\
\hline VC8 industrial & 0,005 & 1,1 & 5,1 \\
\hline VC8 grinded & 0,01 & 68,4 & 50,5 \\
\hline VC8 grinded annealed & 0,008 & 24,8 & 31,1 \\
\hline TN20 industrial & 0,027 & 3,8 & 24,2 \\
\hline TN20 grinded & 0,04 & 25,2 & 31,4 \\
\hline
\end{tabular}

Thus, the abrasive capacity of the VC8 grinded powder is 1.6 times more than that of the annealed powder. The abrasive capacity of the TN20 grinded powder is 1.4 times more than that of the industrial powders. After the ultrasonic impacts, the specific surface of the VC8 and TN20 industrial powders increased by 5 times and 7 times, respectively. As for the specific surface of the grinded powders, it increased by 1.25 times, which proves the increase in the contact compression strain of the powders obtained by the electro-erosive grinding.

\section{Conclusions}

Thus, it is possible to obtain the powders with higher physical and mechanical properties in grinding by the electro-erosive method. 
Besides, the prospects of obtaining powders by the industrial electro-erosive method is determined by a higher efficiency, one stage of the grinding process, high-speed change in the processed metal and the possibility of implementing the unstoppable non-waste technology.

\section{References}

1. G.V. Samsonov, V.K. Vitryanyuk, F.I. CHaplygin, Karbidy vol'frama [Tungsten carbides] (Naukova Duma, Kiev, 1974) (in Russian)

2. A.I. Gusev, Fizicheskaya himiya nestekhiometricheskih tugoplavkih soedinenij[Physical chemistry of nonstoichiometric refractory compounds] (Nauka, Moskva, 1991) (in Russian)

3. A.I. Cusev, A.A. Rempel, A.I. Magerl, Dusorder and Jrder in strongly Nonstoichiometric Compourds: Transition Metal Corbides, Nitrides and Oxides (Springer, Berlin - Heidelberg - New York, 2001)

4. W. Weimer, Carbide, BNitride, and Boride Materals Synthesis and Processing, - Ed. A. (Chapman \&Hall, London, 1997)

5. Y.G. Gogotsi, R.A. Andrievski, Materials Science of Carbides, Nitrides, and Borides, Kluwer Academic Publishers, pp. 247 - 266 (1999)

6. A.S. Kurlov, A.I. Gusev, Fizika i himiya karbidov vol'frama [Physics and chemistry of tungsten carbides] (FIZMATLIT, Moskva, 2014) (in Russian)

7. V.I. Marusina, B.M. Krejchman, V.N. Filimonenko, O nekotoryh fiziko-mekhanicheskih svojstvah karbida vol'frama kubicheskoj modifikacii [On some physicomechanical properties of tungsten carbide of cubic modification], Sverhtverdye materialy, v. 5, pp. 3-5 (1981) (in Russian)

8. G.A. Iskhakova, V.I. Marusina, Kh.M. Rakhimyanov, Determination of the microhardness of tungsten carbide particles produced in the spark discharge, Soviet powder metallurgy and metal ceramics, v. 26 (10), pp. 852-854 (1987)

9. G.A. Iskhakova, V.I. Marusina, Structural state and phase-composition of tungsten carbide particles synthesized in spark discharge, Soviet powder metallurgy and metal ceramics, v. 28 (10), pp. 749-753 (1989)

10. V.I. Marusina, G.A. Iskhakova, Kh.M. Rakhimyanov, Phase and particle-size composition of carbides formed during electric spark erosion machining of tungsten, Soviet powder metallurgy and metal ceramics, v. 31 (10), pp. 870-873 (1992)

11. V.I. Marusina, Kh.M. Rakhimyanov, Perspektivy ispol'zovaniya poroshkov karbida vol'frama, poluchennyh $v$ iskrovom razryade, dlya formirovaniya pokrytij [Prospects for the use of tungsten carbide powders produced in the spark discharge for the formation of coatings], Innovacii v mashinostroenii (InMash - 2015), sbornik trudov VII Mezhdunarodnoj nauchno - prakticheskoj konferencii, 23 - 25 sentyabrya, Kemerovo, Rossiya [Innovations in Mechanical Engineering (InMash - 2015), Proceedings VII International Scientific and Practical Conference, September 23 - 25, Kemerovo, Russia], pp. 333-336 (in Russian) 